\title{
ATITUDE DO CONSUMIDOR EM RELAÇÃO À SOJA E PRODUTOS DERIVADOS ${ }^{1}$
}

\author{
Jorge Herman BEHRENS ${ }^{2, *}$, Maria Aparecida Azevedo Pereira DA SILVA ${ }^{3}$
}

\begin{abstract}
RESUMO
Crenças coletadas de consumidores da cidade de Campinas-SP foram utilizadas para compor um questionário de pesquisa de atitude com relação à soja. Um total de cem indivíduos respondeu à pesquisa que, além dos itens de atitude, também avaliou o grau de aceitação e freqüência de consumo de soja e alguns produtos derivados. Os resultados indicaram baixo consumo de produtos de soja pelos entrevistados. A avaliação da atitude revelou concordância que soja é uma boa fonte de proteínas, que o "leite" de soja ajuda a reduzir a gordura corporal, sendo também uma opção para indivíduos alérgicos a leite e que tenham problemas com colesterol. De uma forma geral, a atitude dos entrevistados foi positiva, porém, é recomendável reforçar as alegações de saúde e de nutrição na comunicação dos benefícios do consumo de soja ao consumidor.

Palavras-chave: soja; consumidor; atitude.
\end{abstract}

\section{SUMMARY}

CONSUMER ATTITUDE TOWARDS SOYBEAN AND RELATED PRODUCTS. Consumer beliefs collected in the city of Campinas, SP, were used in an attitude scale about soy. About a hundred subjects answered the survey that also evaluated acceptability and soy products consumption. The collected data showed a low consumption of soy products among the respondents. The respondents agreed with health and nutritional beliefs such as body fat reduction, soy as a good source of proteins and soymilk as an alternative for those individuals who has allergy to milk and are concerned about cholesterol. Attitude towards soy products were considered positive but health and nutritional claims should be reinforced in information to consumers about the benefits of their consumption.

Keywords: soy; consumer; attitude.

\section{1 - INTRODUÇÃO}

Estudos recentes mostrando a relação entre dieta e saúde, somados ao crescente interesse de alguns indivíduos em consumir alimentos mais "saudáveis", têm levado a indústria alimentícia ao desenvolvimento de novos produtos cujas funções pretendem ir além do fornecimento de nutrientes básicos e da satisfação do paladar do consumidor. Esses produtos são conhecidos como "alimentos funcionais" e têm como principal função a redução do risco de doenças crônico-degenerativas. Eles representam um novo segmento dentro do mercado de alimentos e possuem como principais apelos de venda suas alegações de saúde, que são, via de regra, veiculadas pelo rótulo e pela propaganda, com a finalidade de gerar expectativa positiva nos consumidores, induzindo-os à compra [2].

Segundo a Leatherhead Food Research Association (Reino Unido), alimentos com alegações de beneficios à saúde representarão nos próximos anos cerca de cinco por cento do mercado mundial de alimentos, com um faturamento próximo a US\$ 100 bilhões [9]. No Brasil, este mercado é ainda incipiente, porém com um grande potencial, considerando-se a disponibilidade de

\footnotetext{
1. Recebido para publicação em 01/08/2003. Aceito para publicação em 20/05/2004 (001181)

2. Depto. Alimentos e Nutrição Experimental - Faculdade de Ciências Farmacêuticas - Universidade de São Paulo. Av. Professor Lineu Prestes, 580, Bloco-14, CEP: 05508-900, São Paulo-SP.

${ }^{3}$ Depto. Planejamento Alimentar e Nutrição - Faculdade de Engenharia de Alimentos - Universidade Estadual de Campinas. Caixa Postal 6121, CEP: 13083-970, Campinas-SP.

* A quem a correspondência deve ser enviada.
}

fontes naturais, a capacidade produtiva da indústria local e o tamanho do mercado consumidor.

Dentre os alimentos cujas alegações de saúde têm sido amplamente divulgadas pela mídia nos últimos anos destaca-se a soja. Suas características químicas e nutricionais a qualificam como um alimento funcional: além da qualidade de sua proteína, estudos mostram que a soja pode ser utilizada de forma preventiva e terapêutica no tratamento de doenças cardiovasculares, câncer, osteoporose e sintomas da menopausa [8].

Pelo exposto, os beneficios da soja à saúde humana são claramente um ponto importante para a promoção deste alimento junto ao consumidor, desde que eficientemente informados, apontando os beneficios de sua ingestão sobre a saúde e, desta forma, desenvolvendo ou reforçando uma atitude positiva do indivíduo em relação ao produto [2].

Apesar do grande potencial do "leite" de soja, este obteve, no passado, baixa aceitação no Brasil, basicamente devido ao sabor e aroma desagradáveis ao paladar dos consumidores brasileiros. A ação de enzimas presentes nos grãos de soja sobre os ácidos graxos polinsaturados confere ao produto final um sabor que lembra feijão cru.

Entretanto, recentemente a indústria nacional tem feito uso de novas tecnologias na obtenção do "leite" de soja para o mercado brasileiro que apresenta melhor qualidade sensorial. Novos produtos comerciais à base de extrato hidrossolúvel em combinação com sucos de frutas têm obtido êxito no mercado, indicando que os consumidores podem estar mudando sua atitude em relação aos produtos à base de soja. 
Atitude é uma predisposição aprendida pelo indivíduo, formada a partir de suas experiências e informações obtidas, as quais o influenciam a agir favorável ou desfavoravelmente em relação a um determinado "objeto". Este "objeto" pode ser um produto ou categoria de produtos, marcas, serviços, bens, pessoas, conceitos/idéias, propaganda, preço, canais de comércio, mídia, entre outros [11].

A psicologia considera que a atitude seja formada por três componentes básicos e inter-relacionados, sendo o primeiro o componente cognitivo - relativo ao aprendizado e à experiência do indivíduo com relação ao objeto em estudo -, o segundo refere-se ao componente afetivo - o qual reflete o grau de aceitação/preferência do indivíduo em relação ao objeto em questão e, por último, o componente motivacional - associado à tendência do indivíduo à ação [7, 10].

Para estudar o comportamento do consumidor e avaliar a atitude com relação a um determinado produto, técnicas de pesquisa qualitativa e quantitativa são utilizadas de forma a: 1) segmentar o mercado identificando os consumidores potenciais do produto e caracterizando suas demandas, expectativas etc., 2) descobrir fatores que motivem um grupo de individuos a agir de uma forma específica, selecionando marcas ou produtos específicos no momento da compra e, finalmente, 3) explorar crenças e opiniões dos consumidores acerca do produto [6]. Estas informações possibilitam à empresa o desenvolvimento de embalagem, de rótulo e de alegações de campanhas publicitárias que informem sobre características e propriedades do produto, de forma a elevar a expectativa no consumidor em relação ao produto e incentivar a compra do mesmo.

A pesquisa quantitativa tem por finalidade revelar de que forma, com que freqüência e em que grau o indivíduo reage a uma certa idéia apresentada a ele/ela na forma de uma frase, por exemplo, "Alimentos funcionais curam doenças". Em pesquisas de avaliação de atitudes cada frase é denominada "item" e um conjunto de itens sobre um determinado tema constitui a "escala" de atitude. O grau de concordância ou discordância de indivíduos, com relação a cada item de uma escala, permite avaliar um conjunto de crenças ou conceitos identificando aqueles que mais contribuem na formação da atitude de uma população com relação ao tema abordado [7, 10].

Uma das metodologias mais utilizadas para avaliar atitudes de consumidores é a escala de Likert de sete pontos, sendo 7 o maior grau de concordância com a idéia expressa pelo item $(7=$ concordei muitíssimo) e, inversamente, 1 representa o maior grau de discordância do item (1=discordei muitíssimo). Um questionário composto por um conjunto de itens é aplicado a um grupo de cerca de 100 indivíduos e para cada um dos itens é calculado uma média, desvio padrão e distribuição de freqüências dos valores da escala. Em complementação é calculado o coeficiente de Cronbach, uma medida da confiabilidade da escala como medidora da atitude dos indivíduos em relação ao tema/objeto [3, 10].
O presente trabalho teve como objetivo avaliar, junto ao consumidor de nível educacional médio e alto, as crenças, atitudes e hábitos de consumo com relação à soja e seus derivados.

\section{2 - MATERIAL E MÉTODOS}

Por se tratar de pesquisa envolvendo seres humanos, a metodologia descrita a seguir cumpriu os termos da Resolução n. 196 (10/10/1996), do Conselho Nacional de Saúde [4].

\section{1 - Levantamento de crenças, opiniões e nivel de conhecimento dos consumidores}

Crenças, opiniões e nivel de conhecimento do consumidor adulto sobre soja e produtos derivados foram inicialmente levantados através de um questionário, segundo modelo sugerido por MUELLER [10]. Este questionário solicitava que os indivíduos formulassem cinco frases que encerrassem crenças e conhecimentos sobre soja e ficou disponibilizado na homepage da Faculdade de Engenharia de Alimentos da UNICAMP (http:// www.fea.unicamp.br) entre os meses de março e maio de 2000. Indivíduos que acessaram o referido site foram incentivados, através de um link na página, a responder ao questionário. Em complementação, o mesmo questionário foi aplicado - em versão impressa - a freqüentadores de uma academia de esportes da cidade de Campinas, Estado de São Paulo, durante o mesmo período.

Um total de 60 indivíduos (38 do sexo feminino e 22 do sexo masculino) respondeu o referido questionário, sendo 25 provenientes da academia de esportes e 35 do questionário disponibilizado na homepage da FEAUNICAMP.

\section{2 - Elaboração da escala de avaliação de atitude}

A partir do conjunto de crenças, conhecimentos e opiniões obtido na etapa inicial da pesquisa (item 2.1), uma escala de avaliação de atitude em relação à soja e produtos derivados foi construída, de acordo com a metodologia proposta por MUELLER [10].

Esta escala continha 26 itens (frases) sobre soja e produtos derivados, sendo metade deles de caráter negativo e a outra metade de caráter positivo.

A validade e poder de segmentação da escala formulada foram testados seguindo-se procedimento sugerido por MULLER [10]. Nesta etapa, a escala de atitude foi testada com um grupo de 50 indivíduos, consumidores dos produtos em questão, sendo 25 do sexo masculino e 25 do sexo feminino, alunos de graduação, pós-graduação e funcionários da Universidade Estadual de Campinas. Esses indivíduos foram abordados no campus universitário e solicitados a responder a pesquisa, de acordo com sua disponibilidade, interesse e conhecimento e consumo de soja e derivados.

Os respondentes leram cada uma das frases e a expressaram o grau com que concordaram ou discordaram de cada item através da escala de Likert de 7 pontos. 
Após a coleta das respostas, os itens positivos da escala receberam os valores atribuídos a cada categoria: na categoria "concordo muito" foi computada a nota 7; na categoria "concordo moderadamente", foi computada nota 6 , e assim por diante até nota 1 na categoria "discordo muito". Os itens negativos foram inversamente computados: a categoria "concordo muito" recebeu nota 1 e a categoria "discordo muito" recebeu nota 7 .

Os dados assim computados foram estatisticamente analisados calculando-se o índice de discriminação de cada item, que consistiu no coeficiente de correlação de Pearson obtido ao correlacionarem-se as notas que os respondentes deram para cada item com a soma total das notas obtidas por todos os itens da escala, conforme descrito por MUELLER [10]. Itens apresentando indices de discriminação próximos ou inferiores a zero deveriam ser eliminados do questionário.

\section{3 - Avaliação final}

Através do procedimento de validação da escala descrito no item 2.2 , os 26 itens originais sobre soja e produtos derivados foram mantidos, pois todos apresentaram indices de discriminação positivos e distantes de zero.

Assim, um questionário final de pesquisa, contendo os 26 itens sobre soja e produtos derivados foi reaplicado a um total de 100 indivíduos. Destes, 50 eram do sexo feminino e 50 do sexo masculino, recrutados entre alunos de graduação, pós-graduação, funcionários e professores da UNICAMP, e selecionados em função de apreciarem e consumirem soja e produtos derivados.

Com a finalidade de caracterizar a população entrevistada e obter informações sobre seus hábitos de consumo, foram incluídas perguntas sobre a faixa etária, sexo e grau de escolaridade dos respondentes, bem como o grau de aceitação e freqüência de consumo de soja e alguns produtos derivados. O grau de aceitação dos produtos foi avaliado através da escala hedônica estruturada de nove pontos (1=desgosto muitíssimo, 5 = não gosto/nem desgosto, 9 = gosto muitíssimo) .

O questionário final aplicado durante os meses de junho e julho de 2000 está apresentado no Anexo 1.

Os dados de atitude obtidos na avaliação final foram estatisticamente analisados da seguinte forma:

1) os itens positivos da escala receberam os valores atribuídos a cada categoria: na categoria "concordo muito" foi computada a nota 7; na categoria "concordo moderadamente", foi computada nota 6 , e assim por diante até nota 1 na categoria "discordo muito. Os itens negativos foram inversamente computados: a categoria "concordo muito" recebeu nota 1 e a categoria "discordo muito" recebeu nota 7 ;

2) porcentagem de respostas de cada categoria da escala de Likert, para cada item do questionário;

3) cálculo do coeficiente de Cronbach, também conhecido como "alfa":

$$
\begin{aligned}
& \text { Alfa }=(\mathrm{k} / \mathrm{k}-1)\left[1-\left(\sum \mathrm{s}_{\mathrm{i}}^{2} / \mathrm{s}_{\mathrm{t}}^{2}\right)\right] \\
& \text { Sendo: } \\
& \mathrm{k}=\text { número de itens que compõem a escala } \\
& \mathrm{s}_{\mathrm{i}}^{2}=\text { variância de cada item da escala } \\
& \mathrm{s}_{\mathrm{t}}^{2}=\text { variância total }
\end{aligned}
$$

\section{3 - RESULTADOS E DISCUSSÃO}

\section{1 - Caracterização da população estudada}

Dos 100 individuos respondentes do questionário final (50 do sexo masculino e 50 do sexo feminino), $60 \%$ pertenciam à faixa etária entre 18 e 25 anos, enquanto que os outros $40 \%$ pertenciam à faixa entre 26 e 40 anos. A grande maioria dos entrevistados (90\%) possuía pelo menos o segundo grau completo, sendo que, destes, 50\% haviam concluído algum curso superior.

Desta forma, verificou-se que, por se tratar de um segmento da população universitária, os indivíduos que participaram desta pesquisa foram basicamente de jovens consumidores com alto nível educacional.

\section{2 - Consumo e aceitação de soja e de produtos derivados}

Os dados obtidos mostraram que o tofu e o "leite" de soja foram os produtos mais conhecidos pelos entrevistados. Apenas $40 \%$ deles reportaram nunca ter experimentado esses produtos. Por outro lado, o "iogurte" de soja mostrou-se um produto praticamente desconhecido por essa população: $70 \%$ dos indivíduos declararam nunca ter experimentado este tipo de produto.

Com relação à aceitação, verificou-se que a soja e seus produtos são, de fato, apreciados por um segmento pequeno de entrevistados. A proteína de soja, a soja em grãos, o tofu e o "leite" de soja foram apreciados por cerca de $30 \%$ dos entrevistados, que reportaram gostar destes produtos em um grau entre "ligeiramente" e "muitíssimo".

O consumo de produtos de soja reportado pelos entrevistados também foi baixo. A proteína, o "leite" de soja e, em menor grau o tofu, foram os produtos reportados com maior freqüência pelos entrevistados: cerca de 30\% revelaram consumir esses produtos pelo menos uma vez por mês. Por outro lado, o "iogurte" de soja e a soja em grãos praticamente nunca foram consumidos pelos respondentes desta pesquisa.

Cerca de $8 \%$ dos entrevistados disseram consumir "leite" de soja com freqüência igual ou superior a uma vez por semana.

O consumo de proteína de soja nesta população poderia ser justificado pelo fato dos entrevistados serem estudantes e funcionários da UNICAMP que geralmente realizam suas refeições no restaurante universitário. À época da pesquisa, este servia diariamente em seu cardápio a proteína de soja como opção de fonte protéica, o que tornava o produto mais conhecido por estes indivíduos. 
O consumo de "leite" de soja tem aumentado no Brasil em função de novos produtos à base de extrato hidrossolúvel de soja, em combinação com sucos de frutas, que vêm sendo comercializados com sucesso no mercado nacional desde o final da década de 90. Estes produtos possuem sabor agradável e que pouco lembra o sabor característico de "leite" de soja. A presença e a expansão da linha destes produtos no mercado brasileiro nos últimos anos indicam que os consumidores foram receptivos e os incorporaram a seus hábitos alimentares [1].

\section{3 - Avaliação da atitude de consumidores com relação à soja e produtos derivados}

As Tabelas $1 a, 1 b$ e 2 apresentam os itens que compuseram a escala de medida de atitude com relação à soja e produtos derivados, seus respectivos escores médios, freqüência de respostas em cada categoria da escala de Likert e o índice de discriminação de cada item.

No teste preliminar do questionário, nenhum dos itens da escala de medida de atitude sobre soja apresentou índice de discriminação negativo, e poucos se aproximaram de zero. Assim, foi decidido aplicar o questionário final com os 26 itens originalmente formulados (Anexo 1). Entretanto, quando os resultados dos 100 respondentes finais foram computados e analisados, dois itens apresentaram indices negativos (Tabela 1a). Esses itens foram eliminados da escala final, pois diminuíam o poder de segmentação e a confiabilidade da escala, sendo esta última avaliada através do coeficiente de Cronbach.

A escala de atitude em relação à soja e a produtos derivados, considerando-se os 24 itens restantes relacionados nas Tabelas $1 \mathrm{~b}$ e 2, apresentou coeficiente de Cronbach igual a 0,71. De acordo com MUELLER [10], uma escala que apresente este coeficiente igual ou superior a 0,70 é um instrumento confiável para se medir atitudes sobre o objeto relacionado. Assim, a escala apresentada nas Tabelas $1 b$ e 2 pode ser considerada confiável e de poder discriminativo satisfatório uma vez que todos os 24 itens da escala obtiveram indices de discriminação positivos. Quanto maior o valor do índice de discriminação de um item, maior sua contribuição para a escala de medida de atitude. Por outro lado, itens com índices próximos a zero indicam que estes não contribuem para o poder da escala em segmentar os respondentes, provavelmente por não avaliarem questões relevantes ao tema da escala, ou por avaliarem crenças ou idéias de grau de concordância ou discordância praticamente consensual entre os indivíduos.

Através da Tabela $1 b$ observa-se que os itens 3,11 , e 23 foram aqueles com os quais os entrevistados mais concordaram, pois estes obtiveram escores médios que variaram entre 6,37 e 5,57, refletindo maiores freqüências de repostas dos entrevistados entre as categorias "concordo ligeiramente" e "concordo muito", na escala de Likert.
De acordo com as proposições dos itens 3 e 11, os entrevistados concordaram que "soja é uma boa fonte de proteinas" e um alimento promotor de boa saúde. De fato, 93\% dos entrevistados concordaram em um grau igual ou superior a "concordo ligeiramente" que a soja é uma boa fonte de proteínas e $78 \%$, que a soja promove boa saúde. Cerca de $87 \%$ dos entrevistados concordaram com o item 23 que afirma que "o 'leite' de soja é uma opção saudável para aqueles individuos alérgicos a leite". Entretanto, este item apresentou Índice de discriminação próximo a zero, ou seja, revelou uma crença comum para a grande maioria dos indivíduos e que não contribui para segmentar suas opiniões, como os itens 3 e 11 . Esses resultados sugerem que essa população conhece, de um modo geral, o valor da soja como alimento.

Observa-se para os itens 7, 10, 16, 18, 19 e 25 altas freqüências de entrevistados que expressaram suas opiniões através da categoria "não concordo/nem discordo" da escala de Likert. Isto indica que um grande número de indivíduos pareceu desconhecer ou não estar certo das alegações de saúde propostas por estes itens, em especial os itens 7 "O consumo diário de soja na dieta ajuda a reduzir o risco de desenvolvimento de cânceres como de mama e de útero" e 10 "O consumo de soja pelas mulheres ajuda a aliviar os sintomas da menopausa".

Esta pesquisa foi realizada no ano de 2000 e até então pouco se divulgava na mídia sobre os beneficios da soja à saúde. Nos últimos anos a mídia brasileira tem divulgado intensivamente as pesquisas sobre a qualidade nutricional da soja e a relação de sua ingestão com a diminuição do risco de câncer e alivio de sintomas da menopausa. Essas informações recentes podem ter ampliado o nível de informação do consumidor e talvez aumentado o nível atual de concordância com as proposições destes itens.

A ação da soja na prevenção do câncer ginecológico e alivio dos sintomas da menopausa são atribuídos às isoflavonas, compostos fenólicos heterocíclicos que podem atuar como agentes antiestrogênicos, competindo com estrógenos de origem endógena (como o $17 \beta-$ estradiol), cuja função biológica está ligada ao desenvolvimento de alguns tipos de cânceres ginecológicos. Populações do Sudeste Asiático, onde a soja faz parte dos hábitos alimentares, apresentam baixa incidência de câncer estrogênio-dependente e este fato vem a reforçar, de acordo com a opinião de alguns pesquisadores, que a soja deveria fazer parte dos hábitos alimentares das mulheres, a despeito de mais estudos serem necessários antes de se sugerir a ingestão de soja ou extratos de isoflavonas como substitutos da reposição hormonal de mulheres em fase de menopausa e pósmenopausa [8]. Infelizmente esta informação parece não ter ainda atingido a população entrevistada, apesar desta ser considerada de alto nível educacional para os padrões da média nacional. Esses resultados apontam a necessidade de maior veiculação das citadas informações na mídia nacional, notadamente aquela que mais interessa às mulheres. 
TABELA 1a. Proporção das respostas (\%) e escore médio dos ITENS RETIRADOS da escala de atitude em relação a soja e produtos derivados.

\begin{tabular}{|c|c|c|c|c|c|c|c|c|c|}
\hline Itens & $\begin{array}{c}\text { Discordo } \\
\text { muito } \\
(\%)\end{array}$ & $\begin{array}{c}\text { Discordo } \\
\text { moderadamente } \\
(\%)\end{array}$ & $\begin{array}{c}\text { Discordo } \\
\text { ligeiramente } \\
(\%)\end{array}$ & $\begin{array}{c}\text { Não } \\
\text { concordo, } \\
\text { nem } \\
\text { discordo } \\
(\%)\end{array}$ & $\begin{array}{c}\text { Concordo } \\
\text { ligeiramente } \\
(\%)\end{array}$ & $\begin{array}{c}\text { Concordo } \\
\text { moderadamente } \\
(\%)\end{array}$ & $\begin{array}{c}\text { Concordo } \\
\text { muito } \\
(\%)\end{array}$ & $\begin{array}{l}\text { Escore } \\
\text { médio } \\
\text { e } \\
\text { desvio } \\
\text { padrão }\end{array}$ & $\begin{array}{c}\text { İndice } \\
\text { de } \\
\text { discriminação }\end{array}$ \\
\hline $\begin{array}{l}\text { 14. Soja é melhor fonte de } \\
\text { proteínas que carnes de } \\
\text { animais (vaca, frango, } \\
\text { peixe, etc.). }\end{array}$ & 8 & 9 & 15 & 22 & 8 & 16 & 22 & $4,51 \pm 1,94$ & $-0,34$ \\
\hline
\end{tabular}

TABELA 1b. Proporção das respostas (\%) e escore médio dos ITENS POSITIVOS da escala de atitude em relação a soja e produtos derivados.

\begin{tabular}{|c|c|c|c|c|c|c|c|c|c|}
\hline Itens & $\begin{array}{l}\text { Discordo } \\
\text { muito } \\
(\%)\end{array}$ & $\begin{array}{c}\text { Discordo } \\
\text { moderadamente } \\
(\%)\end{array}$ & $\begin{array}{c}\text { Discordo } \\
\text { ligeiramente } \\
(\%)\end{array}$ & $\begin{array}{c}\text { Não } \\
\text { concordo, } \\
\text { nem } \\
\text { discordo } \\
(\%) \\
\end{array}$ & $\begin{array}{c}\text { Concordo } \\
\text { ligeiramente } \\
(\%)\end{array}$ & $\begin{array}{c}\text { Concordo } \\
\text { moderadamente } \\
(\%)\end{array}$ & $\begin{array}{l}\text { Concordo } \\
\text { muito(\%) }\end{array}$ & $\begin{array}{l}\text { Escore } \\
\text { médio } \\
\text { e } \\
\text { desvio } \\
\text { padrão }\end{array}$ & $\begin{array}{c}\text { İndice } \\
\text { de } \\
\text { discriminação }\end{array}$ \\
\hline $\begin{array}{l}\text { 9. Há atualmente boas } \\
\text { bebidas a base de "leite" de } \\
\text { soja no mercado. }\end{array}$ & 7 & 1 & 6 & 29 & 14 & 16 & 27 & $4,99 \pm 1,73$ & 0,37 \\
\hline $\begin{array}{l}\text { 10. O consumo de soja por } \\
\text { mulheres ajuda a aliviar os } \\
\text { sintomas da menopausa. }\end{array}$ & 1 & 1 & 2 & 70 & 7 & 9 & 10 & $4,48 \pm 1,12$ & 0,21 \\
\hline $\begin{array}{l}\text { 11. "Soja na mesa é } \\
\text { saúde!". }\end{array}$ & 1 & 1 & 3 & 17 & 19 & 30 & 29 & $5,57 \pm 1,29$ & 0,44 \\
\hline $\begin{array}{l}\text { 16. O "leite" de soja é mais } \\
\text { seguro que o leite porque } \\
\text { não contém antibióticos. }\end{array}$ & 8 & 9 & 10 & 48 & 10 & 8 & 7 & $3,97 \pm 1,50$ & 0,17 \\
\hline $\begin{array}{l}\text { 18. O "leite" de soja é mais } \\
\text { saudável que o leite por } \\
\text { não conter hormônios. }\end{array}$ & 7 & 8 & 10 & 46 & 16 & 5 & 8 & $4,05 \pm 1,47$ & 0,15 \\
\hline $\begin{array}{l}\text { 19. O consumo de soja } \\
\text { ajuda a fortalecer os ossos. }\end{array}$ & 9 & 8 & 9 & 53 & 11 & 3 & 7 & $3,86 \pm 1,44$ & 0,30 \\
\hline $\begin{array}{l}\text { 20. "Criança alimentada } \\
\text { com soja é criança forte". }\end{array}$ & 5 & 6 & 8 & 37 & 25 & 7 & 12 & $4,40 \pm 1,49$ & 0,39 \\
\hline $\begin{array}{l}\text { 22. O "leite" de soja ajuda a } \\
\text { reduzir o colesterol. }\end{array}$ & 0 & 2 & 2 & 41 & 14 & 23 & 18 & $5,11 \pm 1,29$ & 0,13 \\
\hline $\begin{array}{l}\text { 25. Soja ajuda a equilibrar a } \\
\text { flora intestinal. }\end{array}$ & 2 & 3 & 4 & 52 & 12 & 14 & 12 & $4,63 \pm 1,35$ & 0,20 \\
\hline
\end{tabular}


TABELA 2. Proporção das respostas (\%) e escore médio das proposições dos ITENS NEGATIVOS sobre soja e produtos derivados.

\begin{tabular}{|c|c|c|c|c|c|c|c|c|c|}
\hline Itens & $\begin{array}{l}\text { Discordo } \\
\text { muito } \\
(\%)\end{array}$ & $\begin{array}{c}\text { Discordo } \\
\text { moderadamente } \\
(\%)\end{array}$ & $\begin{array}{c}\text { Discordo } \\
\text { ligeiramente } \\
(\%)\end{array}$ & $\begin{array}{l}\text { Não } \\
\text { concordo, } \\
\text { nem } \\
\text { discordo } \\
(\%) \\
\end{array}$ & $\begin{array}{l}\text { Concordo } \\
\text { ligeiramente } \\
(\%)\end{array}$ & $\begin{array}{c}\text { Concordo } \\
\text { moderadamente } \\
(\%)\end{array}$ & $\begin{array}{l}\text { Concordo } \\
\text { muito } \\
(\%)\end{array}$ & $\begin{array}{l}\text { Escore } \\
\text { médio } \\
\text { E } \\
\text { Desvio } \\
\text { padrão }\end{array}$ & $\begin{array}{c}\text { İndice de } \\
\text { discriminação }\end{array}$ \\
\hline $\begin{array}{l}\text { 2. Os produtos de soja são } \\
\text { de difícil digestão. }\end{array}$ & 3 & 4 & 11 & 18 & 11 & 19 & 33 & $5,19 \pm 1,72$ & 0,24 \\
\hline $\begin{array}{l}\text { 4. Os produtos de soja } \\
\text { encontrados no mercado } \\
\text { são geralmente caros. }\end{array}$ & 13 & 13 & 14 & 44 & 7 & 5 & 3 & $3,45 \pm 1,45$ & 0,03 \\
\hline $\begin{array}{l}\text { 5. Para fortalecer os ossos } \\
\text { o leite é melhor que o } \\
\text { "leite" de soja. }\end{array}$ & 23 & 25 & 6 & 26 & 8 & 6 & 4 & $3,03 \pm 1,73$ & 0,26 \\
\hline $\begin{array}{l}\text { 8. O leite contém mais } \\
\text { vitaminas que o "leite" de } \\
\text { soja. }\end{array}$ & 3 & 19 & 14 & 41 & 10 & 3 & 10 & $3,88 \pm 1,53$ & 0,50 \\
\hline $\begin{array}{l}\text { 12. É preciso desenvolver } \\
\text { produtos de soja com } \\
\text { melhor sabor. }\end{array}$ & 60 & 20 & 11 & 5 & 1 & 1 & 2 & $1,83 \pm 1,37$ & 0,14 \\
\hline $\begin{array}{l}\text { 13. O único produto de soja } \\
\text { amplamente } \\
\text { comercializado é o seu } \\
\text { óleo. }\end{array}$ & 32 & 19 & 14 & 6 & 5 & 6 & 18 & $3,27 \pm 2,29$ & 0,09 \\
\hline $\begin{array}{l}\text { 17. O "leite" de soja é } \\
\text { menos seguro que o leite } \\
\text { por que pode conter } \\
\text { resíduos de pesticidas. }\end{array}$ & 4 & 11 & 14 & 50 & 6 & 4 & 11 & $3,97 \pm 1,48$ & 0,13 \\
\hline
\end{tabular}

Os itens 15, 22 e 24 também receberam alta concordância por significativo número de entrevistados. Cerca de $60 \%$ concordam em grau ligeiramente ou superior que "consumir 'leite' de soja é melhor que consumir leite para quem tem problemas com colesterol", enquanto $55 \%$ concordam que "o 'leite' de soja ajuda a reduzir o colesterol" e 59\% concordam que "substituir o leite pelo 'leite' de soja contribui para diminuir a gordura corporal'. Estes resultados indicam que esses individuos encontram-se bastante cientes da associação entre consumo de "leite" de soja e benefícios relacionados à redução de colesterol e índice de gordura corporal. Ainda assim, entre $31 \%$ e $36 \%$ dos indivíduos atribuíram nota 4 a essas frases, indicando que não concordam nem discordam destas afirmativas, o que sugere que desconhecem os citados efeitos da soja na saúde humana.

A falta de conhecimento nutricional por razoável proporção dos entrevistados também pode ser visualizada através do padrão das respostas obtidas pelos itens 8 "o leite contém mais vitaminas que o 'leite' de soja", 14 "soja é melhor fonte de proteinas que carne de animais", 19 "O consumo de soja ajuda a fortalecer os ossos" e 25 "Soja ajuda a equilibrar a flora intestinal", os quais receberam concordância entre $21 \%$ e 38\% dos entrevistados.

O "leite" de soja pode ser preparado para que tenha o mesmo teor de proteínas que o leite. Entretanto, o valor biológico das proteínas de soja $(0,7)$ é inferior ao das proteínas contidas no leite $(0,9)$, tendo-se como referencial as proteínas do ovo $(1,0)$, reconhecidas como as de maior valor biológico. Além disso, o leite é também uma excelente fonte de cálcio, fósforo e vitaminas $\mathrm{B}_{2}$ e $\mathrm{B}_{12}$, entre outros nutrientes, sendo considerado um alimento quase completo. Assim, o "leite" de soja tem realmente valor nutricional inferior ao leite [5].

Na Tabela 2 estão listados os itens de caráter negativo sobre soja e produtos derivados. Verifica-se que 
apenas 55\% dos entrevistados concordaram com a preposição do item 1 "O 'leite' de soja tem menor valor nutricional que o leite". Porém, 54\% entrevistados discordaram da proposição do item 5 "Para fortalecer os ossos, o leite é melhor que o 'leite' de soja”, sendo que esta é uma afirmativa verdadeira.

O leite é uma excelente fonte de cálcio sendo que o consumo de um copo de leite (cerca de 250mL) prove $32 \%$ da ingestão diária recomendada (IDR) deste mineral essencial na composição dos ossos [12].

Quanto à digestibilidade, a soja apresenta em seus grãos oligossacarídeos que não são hidrolisados durante o processo de digestão e, portanto, podem causar flatulência, o que talvez leve os entrevistados a considerar os produtos de soja de dificil digestão (item 2). Por outro lado, o item 6 na Tabela 2, com a preposição "Soja e seus produtos derivados causam flatulência (gases)" recebeu a alternativa "nem concordo/nem discordo" de 50\% dos entrevistados, indicando que esses indivíduos não associam má digestão à flatulência.

Com respeito ao sabor do "leite" de soja, cerca de 91\% dos entrevistados discordaram que "É preciso desenvolver novos produtos de soja com melhor sabor" e que "O sabor do 'leite' de soja é desagradável" (itens 12 e 21). Apenas 15\% concordaram com esta última afirmativa. Esses resultados vêm de encontro ao fato de atualmente produtos à base de extrato hidrossolúvel de soja encontrarem boa aceitação junto aos consumidores brasileiros devido à utilização de extratos de soja de melhor qualidade, com menor intensidade de sabor característico de feijão cru. A idéia expressa pelo item 21 é complementada pelo item 9 da Tabela 1 "Há atualmente boas bebidas à base de 'leite' de soja no mercado", que sugere que cerca de $57 \%$ dos entrevistados já provaram as bebidas presentes no mercado (como Ades ${ }^{\circledR}$ e Tonyu ${ }^{\circledR)}$ e as apreciaram.

Com relação aos itens 4 e 26 da Tabela 2, 40\% das respostas indicam discordância dos entrevistados quanto a "evitar a ingestão de alimentos de soja transgênica e que os produtos de soja são caros para a maioria da população". Com respeito à soja transgênica, no ano 2000 este assunto ainda não despontava na mídia como tem ocorrido atualmente, por força da proibição do plantio e comercialização de transgênicos no Brasil. Seria interessante avaliar a atitude do consumidor brasileiro em relação aos transgênicos e verificar se suas crenças e conhecimentos são positivos ou negativos.

Em se tratando do preço dos produtos de soja, as poucas opções de produtos são encontradas com preços competitivos no mercado paulista. O preço, então, não deveria ser um fator limitante do consumo, que dependeria muito mais de esforços de marketing.

A despeito dos consumidores brasileiros praticamente desconhecerem o "iogurte" de soja, apenas $14 \%$ dos entrevistados concordaram com o item 14 " $O$ 'iogurte' de soja tem sabor ruim", sendo que a maioria (63\%) nem concordou/nem discordou desta afirmativa. Esses resultados indicam uma atitude "neutra" dos entrevis- tados com relação ao "iogurte" de soja. Assim, este resultado sugere uma oportunidade de mercado para o "iogurte" de soja no Brasil.

\section{4 - CONCLUSÕES}

Os resultados da presente pesquisa indicaram que o consumo de soja e produtos derivados era baixo entre os consumidores que responderam ao questionário, entre junho e julho de 2000. Poucos indivíduos reportaram o consumo freqüente de produtos de soja, sendo que a proteína, o "leite" de soja e o tofu foram indicados como os produtos mais conhecidos e consumidos pelos mesmos. Por outro lado, o "iogurte" de soja e a soja em grãos foram produtos praticamente desconhecidos desses indivíduos.

$\mathrm{Na}$ avaliação da atitude, os entrevistados concordaram que a soja é uma boa fonte de proteínas, que o consumo de "leite" de soja ajuda a reduzir a gordura corporal, sendo também uma opção para indivíduos alérgicos ao leite e que tenham problemas com colesterol. Entretanto, houve grande freqüência de respostas na categoria "não concordo/nem discordo" da escala de Likert em vários itens que se relacionavam às alegações de saúde, como a diminuição do risco de desenvolvimento de câncer ginecológico e alívio de sintomas da menopausa. Isto evidenciou a falta de informação dos respondentes sobre vantagens e beneficios do consumo regular de soja na dieta, na época em que a pesquisa foi realizada.

Em conclusão, as indústrias alimentícias que desejam lançar no mercado produtos à base de soja devem investir tanto nos aspectos sensoriais do produto, como na divulgação dos benefícios do consumo de soja à saúde humana, a fim de levantar expectativas positivas nos consumidores e estimular a compra e o consumo destes produtos.

\section{5 - REFERÊNCIAS BIBLIOGRÁFICAS}

[1] AIZO, S. Setor de sucos atrai gigante sucro-alcooleira. Engarrafador Moderno, v. 8, n. 54, p. 8-10,12, 1997.

[2] BEHRENS, J.H.; ROIG, S.M.; DA SILVA, M.A.A.P. Aspectos de Funcionalidade, de Rotulagem e de Aceitação de Extrato Hidrossolúvel de Soja Fermentado e Culturas Lácteas Probióticas. Boletim SBCTA, v. 34, n. 2, p. 99-106, 2001.

[3] BOVÉE, C.L.; THILL, J.V.; DOVEL, G.P.; WOOD, M.B.1995. Advertising Excellence. New York: McGraw-Hill, Inc. $712 \mathrm{p}$.

[4] BRASIL. Ministério da Saúde. Conselho Nacional de Saúde. Resolução n. 196, de 10 de outubro de 1996.Diário Oficial da União, Brasília, 10 out.1996. 9p.

[5] Cheftel, J.C; CUQ, J.; LORIEnT, D.1985. Amino Acids, Peptides and Proteins. In: Fennema, O.R., editor. Food Chemistry, New York: Marcel Dekker, Inc. p. 401-445.

[6] COHEN, J. C. Applications of Qualitative Research for Sensory Analysis and Product Development. Food Technology, n. 11, p. 164, 166, 174, 1990.

[7] GADE, C. 1980. Psicologia do Consumidor. São Paulo:Editora Pedagógica Universitária Ltda. 186p. 
[8] HASLER, C.M. Functional Foods: Their Role in Disease Prevention and Health Promotion. Food Technology, v.52, n.11,1998.

[9] MARTIN, C. The Elixir of Life. Chemistry in Britain, v. 8, p. 56-58, 1996.

[10] MUELLER, D.J. 1986. Measuring social attitudes: a handbook for researchers and practioners. New York: Teachers College. 179p.

[11] SCHIFFMAN, L.G.; KANUK, L.L. 2000. Consumer Behavior. New Jersey: Prentice Hall, Inc. 608p.

[12] SWAISGOOD, H.E. 1985. Characteristics of Edible Fluidsof animal Origin: Milk. In: Fennema, O.R., editor. Food Chemistry. New York: Marcel Dekker, Inc. p. 791-828.

\section{6 - AGRADECIMENTOS}

Os autores agradecem ao CNPq (Conselho Nacional de Pesquisa) pelo financiamento da pesquisa.

\section{UNIVERSIDADE ESTADUAL DE CAMPINAS \\ FACULDADE DE ENGENHARIA DE ALIMENTOS \\ DEPARTAMENTO DE TECNOLOGIA DE ALIMENTOS}

Estamos fazendo uma pesquisa sobre a atitude do consumidor brasileiro em relação à soja. Sua contribuição será muito importante e bem-vinda, pois nos auxiliará a entender melhor os hábitos do consumidor com relação a estes produtos e gerará informações para o desenvolvimento de novos produtos. Por favor, responda primeiramente as questões abaixo. Não é necessário se identificar. Siga as instruções dos questionários.

\section{I) Dados pessoais:}

Idade :

( ) 18-25 anos ( ) masculino

( ) 26-40 anos \begin{tabular}{|c|} 
Anexo 1: \\
$\begin{array}{l}\text { Modelo de questionário de avaliação de atitude de consumidores sobre } \\
\text { soja e produtos derivados }\end{array}$
\end{tabular}
( ) $1^{\circ}$ grau incompleto

( ) $1^{\circ}$ grau completo

( ) $2^{\circ}$ grau incompleto

( ) $2^{\circ}$ grau completo

( ) superior

( ) pós-graduado
Escolaridade:

\begin{tabular}{lcc}
\hline \multicolumn{1}{c}{ Alimento } & $\begin{array}{c}\text { Nunca } \\
\text { Experimentei }\end{array}$ & $\begin{array}{c}\text { Quanto você gosta do } \\
\text { alimento? }\end{array}$ \\
\hline "Leite" de soja & $($ ) & $($ ) \\
"Iogurte" de soja & $($ ) & $($ ) \\
Tofu (queijo de soja) & $($ ) & $($ ) \\
Soja em grãos & $($ ) & $($ ) \\
Proteina de soja & $($ ) & \\
\hline
\end{tabular}

Agora, utilizando a escala abaixo indique a freqüência com a qual você costuma consumir cada um dos produtos listados a seguir:

\begin{tabular}{|c|c|c|c|c|}
\hline $\mathbf{1}$ & $\mathbf{2}$ & $\mathbf{3}$ & $\mathbf{4}$ & $\mathbf{5}$ \\
\hline $\begin{array}{c}\text { Consumo } \\
\text { Muito }\end{array}$ & $\begin{array}{c}\text { Consumo } \\
\text { Moderadamente }\end{array}$ & $\begin{array}{c}\text { Consumo } \\
\text { pouco } \\
\text { (todos os dias) }\end{array}$ & $\begin{array}{c}\text { Consumo } \\
\text { Ocasionalmente } \\
\text { (até três vezes por semana) }\end{array}$ & $\begin{array}{c}\text { Nunca } \\
\text { Consumo }\end{array}$ \\
\hline
\end{tabular}

\begin{tabular}{|c|c|}
\hline Alimento & Oquanto vocêcansame? \\
\hline Leite & ( ) \\
\hline 'Leite' de soja & () \\
\hline “Iogurte" de soja & () \\
\hline Tơfu (quaijo de soja) & ( ) \\
\hline Soja emgrãos & () \\
\hline Proteina de sgja & $($ ) \\
\hline
\end{tabular}

\section{III) Questionário}

Instruções: As sentenças listadas a seguir expressam crenças e conhecimentos dos consumidores sobre soja e produtos derivados. Leia cada sentença e, usando a escala abaixo, indique o seu grau de concordância ou discordância com cada item. Você deverá dar uma resposta para cada item do questionário.

\section{7. concordo muito}

6. concordo moderadamente

5. concordo ligeiramente

4. nem concordo / nem discordo

3. discordo ligeiramente

2. discordo moderadamente

1. discordo muito

1. __. O "leite" de soja tem menor valor nutricional que o leite.

2. __. Os produtos de soja são de difícil digestão.

3. __. A soja é uma boa fonte de proteínas.

4. __. Os produtos de soja encontrados no mercado são geralmente caros.

5. __. Para fortalecer os ossos o leite é melhor que o "leite" de soja.

6. _. Soja e seus produtos derivados causam flatulência (gases).

7. __ O consumo diário de soja na dieta ajuda a reduzir o risco de desenvolvimento de cânceres como de mama e de útero.

8. __. O leite contém mais vitaminas que o "leite" de soja.

9. __ Há atualmente boas bebidas a base de "leite" de soja no mercado.

10. __. O consumo de soja por mulheres ajuda a aliviar os sintomas da menopausa.

11. __. "Soja na mesa é saúde!".

12. _. É preciso desenvolver produtos de soja com melhor sabor. 
13. __. O único produto de soja amplamente comercializado é o seu óleo.

14. _. Soja é melhor fonte de proteínas que carnes de animais (vaca, frango, peixe, etc.).

15. __. A substituição do leite pelo "leite" de soja contribui para a diminuição da gordura corporal.

16. __. O leite se soja é mais seguro que o leite porque não contém antibióticos.

17. __. O "leite" de soja é menos seguro que o leite por que pode conter resíduos de pesticidas.

18. __ . O "leite" de soja é mais saudável que o leite por não conter hormônios.

19. __. O consumo de soja ajuda a fortalecer os ossos.

20. __. "Criança alimentada com soja é criança forte".

21. __. O sabor do "leite" de soja é desagradável.

22. _. O "leite" de soja ajuda a reduzir o colesterol.

23. _. Para os alérgicos a leite, o "leite" de soja é uma opção saudável.

24. __. Consumir "leite" de soja é melhor que consumir leite para quem tem problemas de colesterol.

25. __. Soja ajuda a equilibrar a flora intestinal.

26. __. Deve-se evitar o consumo de um produto a base de soja transgênica. 